\title{
Aplicações Següenciais de Fomesafen Via Água de IrRigação por ASPERSÃo No CONTROLE DE Bidens pilosa ${ }^{1}$
}

\author{
Sequential Applications of Fomesafen Using Sprinkler Irrigation Water for Bidens pilosa \\ Control
}

\begin{abstract}
VIEIRA, R.F. ${ }^{2}$, COSTA, E.L. ${ }^{3}$, WERLANG, R.C. ${ }^{4}$, CUNHA, J.P.A.R. ${ }^{5}$ e RUAS, R.A.A. ${ }^{6}$
RESUMO - Foi conduzido um ensaio em casa de vegetação com o objetivo de avaliar a eficácia da aplicação seqüencial de pequenas doses do fomesafen por via da água de irrigação (herbigação) por aspersão no controle de Bidens pilosa. Os tratamentos foram dispostos no

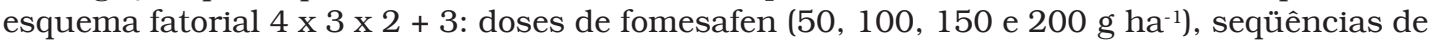
dias após a emergência (DAE) de B. pilosa em que foram realizadas as aplicações do herbicida (7-14-21, 14-21-28 e 21-28-35 DAE), métodos de aplicação (pulverização e herbigação), mais três testemunhas sem herbicida (uma para cada idade da planta daninha). As três idades de B. pilosa foram conseguidas com a semeadura a intervalos de sete dias. Foi empregado o delineamento inteiramente casualizado, com três repetições. Cada unidade experimental constou de um vaso com $12 \mathrm{~L}$ de solo, onde 50 sementes de B. pilosa foram distribuídas. A primeira aplicação, em cada seqüência de dias, foi feita com um quarto da dose; a segunda, com um quarto; e a terceira, com metade da dose. Foi empregado um pulverizador costal de $\mathrm{CO}_{2}$ com volume de calda equivalente a $200 \mathrm{~L} \mathrm{ha}^{-1}$. A herbigação foi feita com um simulador de irrigação $\left(4,52 \mathrm{~mm}\right.$ ou $\left.45.200 \mathrm{~L} \mathrm{ha}^{-1}\right)$. Na pulverização, houve excelente controle da planta daninha com as doses de 100, 150 e $200 \mathrm{~g} \mathrm{ha}^{-1}$, independentemente da seqüência de dias da aplicação. Na herbigação, as aplicações seqüenciais foram ineficazes.
\end{abstract}

Palavras-chave: herbigação, simulador de irrigação, pequenas doses.

\begin{abstract}
A trial was carried out in a greenhouse to evaluate the efficacy of sequential applications of low rates of fomesafen through sprinkler irrigation water (herbigation) for Bidens pilosa control. The following $4 \times 3 \times 2+3$ factorial scheme was used: rates of fomesafen (50, 100, 150 , and $200 \mathrm{~g} \mathrm{ha}^{-1}$ ), sequence of days after emergence (DAE) when herbicide was applied (7-14-21, 14-21-28, and 21-28-35 DAE), application methods (spray and herbigation), and three untreated controls (one for each weed age). Weed ages were obtained by sowing at seven day intervals. A completely randomized design with three replications was used. The experimental unit consisted of a pot with 12 liters of soil, where fifty seeds were sown. The first, second, and third applications in each sequence of days consisted of $1 / 4,1 / 4$ and $1 / 2$ of the total rate, respectively. A $\mathrm{CO}_{2}$ spray was used to apply the herbicide in $200 \mathrm{~L} \mathrm{ha}^{-1}$ of water. For herbigation, a volume of $4.52 \mathrm{~mm}\left(45,300 \mathrm{~L} \mathrm{ha}^{-1}\right)$ of water was applied using an irrigation simulator. Spraying provided excellent weed control at the rates of 100, 150, and $200 \mathrm{~g} \mathrm{ha}^{-1}$, regardless of weed ages. Sequential applications using sprinkler irrigation water proved to be inefficient.
\end{abstract}

Keywords: herbigation, irrigation simulator, low rates.

Recebido para publicação em 15.3.2005 e na forma revisada em 4.8.2006.

2 Pesquisador da Embrapa/Epamig, Vila Gianetti, 47, 36571-000 Viçosa-MG, <rfvieira@ epamig.br>; ${ }^{3}$ Pesquisador da Epamig, Caixa Postal 12, 39440-000 Janaúba-MG. ${ }^{4}$ Doutorando em Fitotecnia, Universidade Federal de Viçosa - UFV, 36570-000 ViçosaMG. ${ }^{5}$ Professor, Instituto de Ciências Agrárias - Universidade Federal de Uberlândia, Campus Umuarama, 38400-902 UberlândiaMG; ${ }^{6}$ Doutorando em Engenharia Agrícola - UFV.

Planta Daninha, Viçosa-MG, v. 24, n. 3, p. 497-503, 2006 


\section{INTRODUÇÃO}

A aplicação tratorizada é o meio mais usado para a distribuição de produtos fitossanitários; nas áreas irrigadas, muitos produtores também vêm empregando a água de irrigação para tal finalidade. Essa técnica, denominada quimigação, teve início no Brasil em meados da década de 1980. Ela proporciona algumas vantagens em relação à aplicação tratorizada: reduz o custo de aplicação, a compactação do solo, o consumo de energia e mão-de-obra; e proporciona maior flexibilidade de aplicação em relação ao estádio de desenvolvimento da cultura e ao período do dia (Vieira \& Silva, 1998). No entanto, essa técnica tem sido empregada de maneira empírica, principalmente no que diz respeito à aplicação de herbicidas para controle de plantas daninhas (herbigação) em pós-emergência, pois é assunto pouco estudado. Segundo Vieira et al. (2003), muitos herbicidas aplicados em pós-emergência são passiveis de serem aplicados, com êxito, via água de irrigação por aspersão. Uma das culturas com maior potencial para aplicação de herbicida por essa técnica é o feijão (Phaseolus vulgaris), em razão da extensa área que ocupa sob pivô central.

Apesar de os resultados de pesquisa com herbicidas aplicados em PÓS via água de irrigação serem relativamente escassos, a revisão de literatura realizada por Vieira et al. (2003) revelou algumas características que eles devem ter para serem eficazes na herbigação: baixa solubilidade em água, rápida absorção foliar e absorção pelas raízes. Segundo esses autores, em geral, esses herbicidas devem apresentar duas dessas três características. Em relação ao fomesafen, apesar da alta solubilidade em água (600.000 $\mathrm{mg} \mathrm{L}^{-1}$ ), as características de relativamente rápida absorção foliar (exige uma hora sem chuva após a aplicação) e de ser absorvido pelas raízes (Monaco et al., 2002) garantem-lhe a eficácia na herbigação quando aplicado na dose recomendada pelo fabricante (Vieira \& Silva, 1998; Vieira et al., 2003). Os herbicidas ineficientes, quando aplicados via água de irrigação, são muito a extremamente solúveis em água e, em geral, têm absorção lenta pelas folhas e/ou não são absorvidos pelas raízes.

Pelos métodos convencionais, o fomesafen é aplicado quando os feijoeiros estão na fase de desenvolvimento V3 (Ferreira et al., 1998), que tem início geralmente entre 11 e 14 dias após a semeadura. Essa etapa inicia-se quando a primeira folha trifoliolada se abre e termina com a abertura da terceira folha trifoliolada; tem duração de cinco a nove dias (Santos \& Gavilanes, 1998). Portanto, normalmente o fomesafen é aplicado entre duas e três semanas após a semeadura. Esse herbicida é mais eficiente quando aplicado com as plantas daninhas em início de desenvolvimento (duas a quatro folhas). Também favorecem a absorção e translocação do fomesafen a umidade relativa acima de $60 \%$ e o solo com alto teor de água. No controle de plantas daninhas como picão-preto é recomendada a dose de 225 a $250 \mathrm{~g} \mathrm{ha}^{-1}$ do i. a. em volume de água de $200 \mathrm{a}$ $300 \mathrm{~L} \mathrm{ha}^{-1}$ (Rodrigues \& Almeida, 1998).

O fomesafen é eficaz quando aplicado por via água de irrigação por aspersão nas doses recomendadas pelo fabricante (Dowler, 1984, 1985; Vieira \& Fontes, 1995; Fontes et al., 1999; Leite et al., 1999, 2002). A retenção, na folhagem, do herbicida aplicado em PÓS via água de irrigação é menor em relação ao aplicado pelos métodos convencionais (Boydston \& Al-khatib, 1993). Qual a razão, então, de esse herbicida ser eficaz na herbigação? Embora essa técnica demande mais estudos para se ter resposta mais consistente a esse questionamento, algumas pistas existem. Os resultados obtidos por Boydston \& Al-khatib (1993) revelam que a absorção pelas plantas de herbicida aplicado via água de irrigação por aspersão é mais rápida, em relação à aplicação pelos métodos convencionais. A razão disso é o microclima (alta umidade relativa do ar e alto teor de água no solo) durante período relativamente longo, em que as plantas são atingidas pela solução diluída do herbicida. Segundo Vieira \& Silva (1998), essas condições mantêm a cutícula das folhas hidratada, favorecendo a absorção do herbicida. Outra alternativa, segundo Devine et al. (1993), é o intumescimento, em condições de alta umidade, dos poros hidrofílicos da cutícula, o que pode facilitar o movimento da molécula de herbicida através dela. Esses autores também aventam a possibilidade de que a penetração de herbicidas pelos estômatos aumente quando a umidade relativa for alta, por causa do efeito desta na abertura dos estômatos. Ademais, Boydston \& Al-khatib (1993) verificaram que 
a superfície foliar exposta ao herbicida pode ser dobrada na herbigação, pois ambas as faces das folhas são atingidas. Embora os efeitos dessas particularidades da herbigação no desempenho de herbicidas aplicados em PÓS não tenham sido bem esclarecidos, a alta umidade proporcionada pela irrigação e o molhamento de ambas as faces das folhas provavelmente favorecem a absorção e a translocação de herbicidas nas plantas. Segundo Hess (1987), após a aplicação de herbicida pelos métodos convencionais, a folha tratada, embora pareça completamente molhada, apresenta, na verdade, uma camada desuniforme de solução de herbicida. Esta, após a evaporação do solvente, dá origem a cristais sobre a superfície das folhas. Em razão de o movimento do herbicida através da cutícula da folha ser por difusão, a sua absorção pela planta só ocorre quando ele se encontra na forma de solução. Portanto, a formação de cristais sobre as folhas reduz a eficiência do herbicida, e essa condição ocorre com maior rapidez quando o herbicida é aplicado pelos métodos convencionais. Na herbigação, em razão do grande volume de água empregado, a absorção radical pode ser importante (Vieira \& Silva, 1998; Monaco et al., 2002).

Na herbigação, a aplicação seqüencial do herbicida pode ser feita de modo prático, sem causar compactação do solo e sem aumento significativo do custo de produção.

O objetivo desta pesquisa foi avaliar a eficácia de aplicações seqüenciais de doses de fomesafen abaixo das recomendadas pelos fabricantes via água de irrigação por aspersão no controle de Bidens pilosa.

\section{MATERIAL E MÉTODOS}

O experimento foi realizado em casa de vegetação da Epamig, localizada no campus da Universidade Federal de Viçosa, em ViçosaMG.

Os tratamentos foram dispostos no esquema fatorial $4 \times 3 \times 2+3$ : doses do fomesafen $\left(50,100,150\right.$ e $\left.200 \mathrm{~g} \mathrm{ha}^{-1}\right)$, seqüências de dias após a emergência (DAE) de B. pilosa em que foram realizadas as aplicações (7-14-21, 14-21-28 e 21-28-35 DAE), métodos de aplicação (pulverização e herbigação) e três testemunhas que não receberam o herbicida (uma para cada fase da planta daninha). As três fases da planta daninha foram conseguidas com a semeadura a intervalos de sete dias. Em ambos os métodos, a primeira aplicação do fomesafen, em cada seqüência, foi feita com um quarto da dose; a segunda, também com um quarto; e a terceira, com metade da dose. Foram empregadas 81 unidades experimentais, correspondendo, cada uma, a um vaso com 12 litros de solo. O delineamento experimental utilizado foi o inteiramente casualizado, com três repetições.

Foram usadas, por vaso, 50 sementes de Bidens pilosa, as quais foram misturadas com o solo localizado a uma profundidade de $1 \mathrm{~cm}$. Foi empregado um solo argiloso com $\mathrm{pH}\left(\mathrm{H}_{2} \mathrm{O}\right)$ $=6,9$, matéria orgânica $=4,21 \mathrm{dag} \mathrm{kg}^{-1}$, CTC efetiva $=8,85 \mathrm{cmol}_{\mathrm{c}} \mathrm{dm}^{-3}$ e saturação por bases $=79 \%$. Os plantios foram feitos em 17.1.2003, 24.1.2003 e 31.1.2003. Em cada época de plantio foram semeados três vasos a mais que o planejado, para, posteriormente, eliminar aqueles com os estandes mais baixos. As aplicações do fomesafen foram feitas em 7, 14 e 21 de fevereiro de 2003. Após a semeadura, todas as unidades experimentais receberam água suficiente para deixar o solo saturado. Em seguida, as irrigações foram feitas diariamente com lâmina de água de $5 \mathrm{~mm}$. Essa lâmina foi elevada, paulatinamente, à medida que a massa vegetal aumentava. Para promover maior incorporação do herbicida no solo e, assim, facilitar a sua absorção pelas raízes, aplicou-se lâmina de água de $15 \mathrm{~mm}$ em todos os tratamentos empregando-se o simulador de irrigação - um dia após as aplicações do fomesafen.

A aplicação convencional foi realizada com pulverizador costal de pressão constante $\left(\mathrm{CO}_{2}\right)$, dotado de uma barra porta-bicos montada com bicos hidráulicos de jato plano standard API 110-02. A altura da barra em relação à parte superior dos vasos e o espaçamento entre os bicos foram de $0,5 \mathrm{~m}$. Foi empregado um volume de calda equivalente a $200 \mathrm{~L} \mathrm{ha}^{-1}$. Para isso, durante as aplicações, a velocidade de deslocamento do aplicador foi de $4 \mathrm{~km} \mathrm{~h}^{-1}$ e a pressão de operação, de $240 \mathrm{kPa}$. As pulverizações foram realizadas entre 8 e 9 horas, quando as temperaturas variaram de 24 a $25{ }^{\circ} \mathrm{C}$ e as umidades relativas, de $80 \%$ a $91 \%$. A altura dos emissores em relação à superfície do solo nos vasos foi de $60 \mathrm{~cm}$. 
A herbigação foi realizada com o simulador de irrigação apresentado na Figura 1. A vazão dos emissores foi de $40 \mathrm{~L} \mathrm{~h}^{-1}$ na pressão de serviço de $398 \mathrm{kPa}$. Após a montagem do simulador, foi avaliada a uniformidade de distribuição de água. Para isso, espalharam-se coletores na área a ser irrigada e funcionou-se o equipamento por dez minutos. Em seguida, a água depositada nos coletores foi medida. Empregou-se o Coeficiente de Uniformidade de Cristhiansen (CUC), cuja porcentagem foi de 97,8 . A lâmina de água empregada nas herbigações foi de $4,52 \mathrm{~mm}$; elas foram realizadas entre $9 \mathrm{~h}$ e $10 \mathrm{~h} 30 \mathrm{~min}$, quando as temperaturas do ar variaram entre 25,7 e $27,2{ }^{\circ} \mathrm{C}$ e as umidades relativas, entre $65 \%$ e $92 \%$.

O grau de controle do picão-preto foi avaliado, visualmente, aos 7, 14 e 21 dias após as aplicações, utilizando-se a escala percentual proposta pela Asociación Latinoamericana de Malezas (1974) (Tabela 1).

Aos 30 dias após a última aplicação do fomesafen, as plantas foram cortadas rente ao solo e secas em estufa a $65{ }^{\circ} \mathrm{C}$, durante 72 horas, para determinação da massa.

Os dados de massa de plantas secas foram submetidos à análise de variância, e as médias foram comparadas pelo teste de Newman Keuls a 5\% de probabilidade. Para comparar as massas de B. pilosa seca das parcelas tratadas com herbicida com as das testemunhas que não receberam o fomesafen, empregou-se o teste de Dunnett a $5 \%$ de probabilidade.

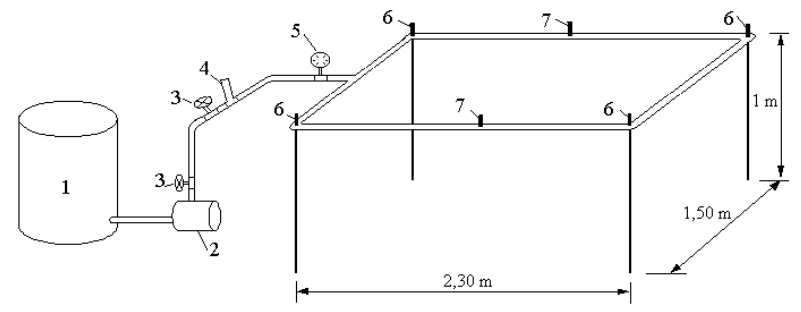

Figura 1 - Simulador de irrigação empregado no estudo $(1$ = depósito de calda de 50 litros, $2=$ motobomba centrífuga de $1 \mathrm{cv}, 3=$ registros, $4=$ filtro de linha, $5=$ manômetro, $6=$ emissores com jato de $90^{\circ}$ e $7=$ emissores com jato de $180^{\circ}$ ).

\section{RESULTADOS E DISCUSSÃO}

Na aplicação com pulverizador, o controle de B. pilosa foi excelente com as doses de 100,
150 e $200 \mathrm{~g} \mathrm{ha}^{-1}$, independentemente da idade das plantas. Na dose de $50 \mathrm{~g} \mathrm{ha}^{-1}$, o controle variou de bom a excelente (Tabela 2). Não houve diferença significativa entre as médias de massa de plantas secas das três seqüências de aplicação, quando o herbicida foi aplicado com pulverizador (Tabela 3). Em todas as doses, independentemente das seqüências de aplicação, houve redução da massa das plantas, em relação à testemunha que não recebeu o fomesafen (Tabela 4). Segundo Lorenzi (2000), B. pilosa é mais suscetivel ao fomesafen no POS inicial ( 2 a 4 folhas) que no PÓS tardio (4 a 8 folhas). Neste estudo, o fomesafen começou a ser aplicado tanto no PÓS inicial quanto no PÓS tardio, e o resultado foi excelente, com exceção da dose de $50 \mathrm{~g} \mathrm{ha}^{-1}$, em que o controle variou de bom a excelente (Tabela 2).

As aplicações seqüenciais por via da água de irrigação foram ineficazes, especialmente quando o herbicida foi distribuído aos 7,14 e $21 \mathrm{DAE}$ (Tabela 2). Sete dias depois da aplicação da primeira dose de um quarto de $200 \mathrm{~g} \mathrm{ha}^{-1}$ do fomesafen por via da água de irrigação, o controle de $B$. pilosa era pobre. Sete dias após a aplicação da segunda dose de um quarto de $200 \mathrm{~g} \mathrm{ha}^{-1}$, o controle era regular na seqüência 14-21-28 e muito bom na 21-28-35 (dados não apresentados). Sete dias após a terceira aplicação (metade de $200 \mathrm{~g} \mathrm{ha}^{-1}$ ), o controle era bom nas seqüências 14-21-28 e 21-28-35. Também na dose de $150 \mathrm{~g} \mathrm{ha}^{-1}$ houve bom controle do picão-preto nessa última data (Tabela 2). No entanto, diferentemente da pulverização, as plantas se recuperaram parcial (caso da seqüência 14-21-28) ou totalmente (seqüência 21-28-35) (Tabela 2). Na herbigação, a menor massa de

Tabela 1 - Escala de avaliação visual proposta pela Asociación Latinoamericana de Malezas

\begin{tabular}{|c|c|c|}
\hline Nota & \% de controle* & Tipo de controle \\
\hline 1 & $0-40$ & Nenhum/pobre \\
2 & $41-60$ & Regular \\
3 & $61-70$ & Suficiente \\
4 & $71-80$ & Bom \\
\hline 5 & $81-90$ & Muito bom \\
\hline 6 & $91-100$ & Excelente \\
\hline
\end{tabular}

* Em relação às testemunhas. 
Tabela 2 - Médias das notas da avaliação visual do controle de Bidens pilosa aos 7, 14, 21 dias após a terceira aplicação do fomesafen, em função das seqüências de dias após a emergência em que foram realizadas as aplicações, das doses e dos métodos de aplicação. Epamig, Viçosa-MG, 2003

\begin{tabular}{|c|c|c|c|c|c|c|c|}
\hline \multirow{3}{*}{$\begin{array}{l}\text { Idades de } B \text {. pilosa } \\
\text { em cada aplicação }{ }^{1 /}\end{array}$} & \multirow{3}{*}{$\begin{array}{l}\text { Dose total } \\
\left(\mathrm{g} \mathrm{ha}^{-1}\right)\end{array}$} & \multicolumn{6}{|c|}{ Dias da avaliação após a terceira aplicação do fomesafen²! } \\
\hline & & \multicolumn{2}{|c|}{7} & \multicolumn{2}{|c|}{14} & \multicolumn{2}{|c|}{21} \\
\hline & & Pulverização & Herbigação & Pulverização & Herbigação & Pulverização & Herbigação \\
\hline \multirow{4}{*}{ 7-14-21 DAE } & 50 & 5 & 1 & 5 & 1 & 4 & 1 \\
\hline & 100 & 6 & 1 & 6 & 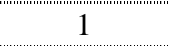 & 6 & 1 \\
\hline & 150 & 6 & 1 & 6 & 1 & 6 & 1 \\
\hline & 200 & 6 & 1 & 6 & 1 & 6 & 1 \\
\hline \multirow{4}{*}{ 14-21-28 DAE } & 50 & 6 & 1 & 5 & 1 & 5 & 1 \\
\hline & 100 & 6 & 1 & 6 & 1 & 6 & 1 \\
\hline & 150 & 6 & 4 & 6 & 2 & 6 & 2 \\
\hline & 200 & 6 & 4 & 6 & 3 & 6 & 2 \\
\hline \multirow{4}{*}{ 21-28-35 DAE } & 50 & 6 & 1 & 5 & 1 & 6 & 1 \\
\hline & 100 & 6 & 1 & 6 & 1 & 6 & 1 \\
\hline & 150 & 6 & 1 & 6 & 1 & 6 & 1 \\
\hline & 200 & 6 & 4 & 6 & 2 & 6 & 1 \\
\hline
\end{tabular}

1/ Dias após a emergência das plântulas. Na primeira, segunda e terceira aplicações foram empregados, respectivamente, um quarto, um quarto e metade da dose total do fomesafen.

ㄴ $1=$ controle nenhum/pobre, $2=$ controle regular, $3=$ controle suficiente, $4=$ controle bom, $5=$ controle muito bom e $6=$ controle excelente.

Tabela 3 - Médias das massas de B. pilosa seca, em gramas, obtidas aos 35 dias após a última aplicação do fomesafen, em função da sequiência de dias após a emergência em que foram realizadas as aplicações e dos métodos de aplicação. Epamig, Viçosa-MG, 2003

\begin{tabular}{|l|c|c|c|}
\hline \multirow{2}{*}{$\begin{array}{c}\text { Método de aplicação } \\
\text { do fomesafen }\end{array}$} & \multicolumn{3}{|c|}{$\begin{array}{c}\text { Dias das aplicações após a emergência de } \\
\text { B. pilosa } \text { (sequiências) }^{1 /}\end{array}$} \\
\cline { 2 - 4 } & $7-14-21$ & $14-21-28$ & $21-28-35$ \\
\hline Herbigação & $6,52 \mathrm{a}$ & $11,67 \mathrm{~b}$ & $18,78 \mathrm{c}$ \\
\hline Pulverização & $0,62 \mathrm{a}$ & $0,91 \mathrm{a}$ & $1,57 \mathrm{a}$ \\
\hline Diferença & $5,90^{* *}$ & $10,76^{* *}$ & $17,20^{* *}$ \\
\hline CV $(\%)$ & 41,7 & 49,5 & 32,1 \\
\hline
\end{tabular}

1/Na primeira, segunda e terceira aplicações foram empregados, respectivamente, um quarto, um quarto e metade da dose total do fomesafen. As médias seguidas da mesma letra na linha não apresentam diferença significativa a $5 \%$ de probabilidade pelo teste de Newman Keuls. $* *=$ Diferença significativa a $1 \%$ de probabilidade pelo teste $\mathrm{F}$.

plantas daninhas secas foi verificada na seqüência 7-14-21 DAE (6,52 g), e a maior, na seqüência 21-28-35 DAE (18,78 g). A massa das plantas pulverizadas foi sempre menor $(\mathrm{P}<0,01)$ que a das plantas que receberam o fomesafen por via da água de irrigação (Tabela 3). Com exceção da dose de $100 \mathrm{~g} \mathrm{ha}^{-1}$, aplicada aos 14, 21 e $28 \mathrm{DAE}$, e da de $200 \mathrm{~g} \mathrm{ha}^{-1}$, aplicada aos 21,28 e $35 \mathrm{DAE}$, não houve redução significativa da massa de plantas que recebeu o herbicida aplicado por via da água de irrigação, em relação à testemunha.

As aplicações seqüenciais semanais do fomesafen (a partir dos 7, 14 ou 21 dias após a emergência) com, respectivamente, um quarto, um quarto e metade da dose recomendada não foram eficazes. Esse herbicida tem uma característica desfavorável à herbigação: a alta solubilidade em água (600.000 $\mathrm{mg} \mathrm{L}^{-1}$ ), o que não lhe prejudica o desempenho quando aplicado uma única vez na dose recomendada (Dowler, 1984, 1985; Vieira \& Fontes, 1995; Fontes et al., 1999; Leite et al., 1999, 2002), talvez em razão da relativamente rápida $a b-$ sorção pelas folhas e da absorção pelas raízes, que disponibilizam quantidade suficiente do ingrediente ativo para que haja controle de plantas daninhas. No entanto, parece que as aplicações de pequenas doses no intervalo de uma semana, e em grande volume de água, não disponibilizam - para absorção pelas folhas e raízes - quantidade suficiente do ingrediente ativo para que $B$. pilosa seja controlada. Na pulverização, no entanto, houve bom a excelente controle da planta daninha mesmo com a dose de $50 \mathrm{~g} \mathrm{ha}^{-1}$. Esse fato parece indicar que a importância da absorção por via 
Tabela 4 - Médias das massas de B. pilosa seca, em gramas, obtidas aos 35 dias após a última aplicação do fomesafen, dos tratamentos em fatorial em relação à testemunha. Epamig, Viçosa-MG, 2003

\begin{tabular}{|c|c|c|c|c|}
\hline \multirow{2}{*}{$\begin{array}{l}\text { Método de aplicação do } \\
\text { fomesafen }\end{array}$} & \multirow{2}{*}{$\begin{array}{c}\text { Dose } \\
\left(\mathrm{g} \mathrm{ha}^{-1}\right)\end{array}$} & \multicolumn{3}{|c|}{ 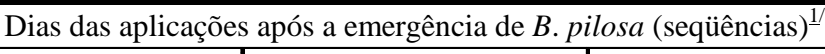 } \\
\hline & & $7-14-21$ & $14-21-28$ & $21-28-35$ \\
\hline \multirow{4}{*}{ Pulverização } & 50 & $1,77 *$ & $2,03 *$ & $3,51 *$ \\
\hline & 100 & $0,26 *$ & $0,70 *$ & $1,18 *$ \\
\hline & 150 & $0,23 *$ & $0,55 *$ & $0,85 *$ \\
\hline & 200 & $0,23 *$ & $0,34 *$ & $0,75 *$ \\
\hline \multirow{4}{*}{ Herbigação } & 50 & 6,70 & 15,73 & 20,59 \\
\hline & 100 & 6,69 & $10,03 *$ & 20,38 \\
\hline & 150 & 6,42 & 10,55 & 20,01 \\
\hline & 200 & 6,25 & 10,37 & $14,12 *$ \\
\hline Testemunha & & 9,67 & 15,16 & 19,47 \\
\hline
\end{tabular}

1/ Na primeira, segunda e terceira aplicações foram empregadas, respectivamente, um quarto, um quarto e metade da dose total do fomesafen. Em cada sequiência de aplicações, as médias seguidas de asterisco diferem da testemunha, a 5\% de probabilidade, pelo teste de Dunnett.

foliar do fomesafen na herbigação é menor do que se pensava. De fato, suas características (alta solubilidade em água, $\log$ Kow $=2,9 \mathrm{em}$ $\mathrm{pH}=1$ e $\mathrm{pKa}=2,7)$ desfavorecem-no quanto à retenção na folha e à velocidade de penetração na camada epicuticular (lipofílica). Portanto, a atividade no solo deve ser o fator mais importante na eficácia desse herbicida por essa técnica. Neste ensaio, no entanto, empregouse solo argiloso com alto teor de matéria orgânica $\left(4,21 \mathrm{dag} \mathrm{kg}^{-1}\right)$. Segundo Weber et al. (1993), a baixa mobilidade do fomesafen no solo pode ser atribuída à sua sorção aos colóides orgânicos e minerais do solo, apesar de sua elevada solubilidade em água e Koc baixo (60 $\mathrm{mL} \mathrm{g}^{-1}$ solo). Em estudo com o objetivo de avaliar a lixiviação do fomesafen aplicado por via da água de irrigação em plantio direto, Fontes et al. (2004) verificaram que ele foi lixiviado até $10 \mathrm{~cm}$ de profundidade já aos 15 dias após a herbigação. Esse estudo foi conduzido em solo com $49 \%$ de argila e 2,83 dag $\mathrm{kg}^{-1}$ de matéria orgânica. É possivel que as doses pequenas do herbicida, especialmente na primeira aplicação, quando as plantas estavam mais jovens e suscetiveis, tenham sido requeridas apenas para saturar a capacidade de sorção do solo. Conseqüentemente, pouco herbicida ficou disponivel na solução do solo para absorção pelas plantas, o que não deve ocorrer quando a dose recomendada é aplicada de uma só vez com as plantas jovens, sobretudo em solo com mais baixo teor de matéria orgânica.
Conclui-se que a aplicação seqüencial do fomesafen em doses abaixo da recomendada pelo fabricante por via da água de irrigação por aspersão é ineficaz.

\section{LITERATURA CITADA}

AHRENS, W. H. Herbicide handbook. 7.ed. Champaign: WSSA, 1994. 352 p.

ASOCIACIÓN LATINOAMERICANA DE MALEZAS. Recomendaciones sobre unificación de los sistemas de evaluación en ensayos de control de malezas. ALAM, v. 1, p. 35-38, 1974.

BOYDSTON, R. A.; AL-KHATIB, K. Efficacy, site of uptake, and retention of bromoxynil in common lambsquarters with conventional and sprinkler application. Weed Sci., v. 41, p. 166-171, 1993.

DEVINE, M. D.; DUKE, S. O.; FEDTKE, C. Physiology of herbicide action. New Jersey: PTR Prentice Hall, 1993. $441 \mathrm{p}$.

DOWLER, C. C. Present herbicide application technology with sprinkler irrigation. Soil Crop Sci. Soc., v. 43, p. 6-9, 1984.

DOWLER, C. C. Herbicides and irrigation technology present and future. In: NATIONAL SYMPOSIUM ON CHEMIGATION, 3., 1985, Tifton. Proceedings... Tifton: USDA-SEA-AR, 1985. p. 58-67.

FERREIRA, F. A. et al. Manejo de plantas daninhas. In: VIEIRA, C.; PAULA Jr., T. J.; BORÉM, A. (Eds.). Feijão: aspectos gerais e cultura no Estado de Minas. Viçosa, MG: Universidade Federal de Viçosa, 1998. p. 325-355. 
FONTES, J. R. A. et al. Aplicação de herbicidas em pósemergência via água de irrigação na cultura do feijão. In: REUNIÃO NACIONAL DE PESQUISA DE FEIJÃO, 6 , 1999, Salvador. Anais... Santo Antônio de Goiás: CNPAF, 1999. p. 459-461.

FONTES, J. R. A. et al. Lixiviação de herbicidas no solo aplicado com água de irrigação em plantio direto. Planta Daninha, v. 22, p. 623-631, 2004.

HESS, F. D. Relationship of plant morphology to herbicide application and absorption. In: McWHORTER, C. G.; GEBHARDT, M. R. (Eds.). Methods of applying herbicides. Champaign: WSSA, 1987. p. 19-35.

LEITE, J. A. O. et al. Aplicação do herbicida fomesafen, com e sem óleo, em três lâminas de água na cultura do feijão. In: REUNIÃO NACIONAL DE PESQUISA DE FEIJÃO, 6. 1999, Salvador. Resumos Expandidos... Santo Antônio de Goiás: CNPAF, 1999. p. 462-4.

LEITE, J. A. O. et al. Fomesafen aplicado via pivô-central na cultura do feijoeiro, em plantio direto e convencional. CONGRESSO NACIONAL DE PESQUISA DE FEIJÃO, 7. 2002, Viçosa. Resumos Expandidos... Viçosa, MG:

Universidade Federal de Viçosa, 2002. p. 465-468.

LORENZI, H. Manual de identificação e controle de plantas daninhas: plantio direto e convencional. 5.ed. Nova Odessa: Instituto Plantarum, 2000. 299 p.

MONACO, T. J.; WELLER, S. C.; ASHTON, F. M. Weed Science: principles and practices. 4.ed. New York: John Wiley \& Sons, 2002. 671 p.
RODRIGUES, B. N.; ALMEIDA, F. S. Guia de herbicidas. 4.ed. Londrina: Edição dos Autores, 1998. 648 p.

SANTOS, J. B.; GAVILANES, M. L. Botânica. In: VIEIRA, C.; PAULA JÚNIOR, T. J.; BORÉM, A. (Eds.). Feijão. Aspectos gerais e cultura no Estado de Minas. Viçosa, MG: Universidade Federal de Viçosa, 1998. p. 55-81.

VIEIRA, R. F.; SILVA, A. A. Aplicação de defensivos via água de irrigação por aspersão. In: VIEIRA, C.; PAULA JÚNIOR, T. J.; BORÉM, A. (Eds.). Feijão. Aspectos gerais e cultura no Estado de Minas. Viçosa: Editora UFV, 1998. p. 267-323.

VIEIRA, R. F.; SILVA, A. A.; RAMOS, M. M.

Aplicação de herbicidas pós-emergentes via irrigação por aspersão - Revisão. Planta Daninha, v. 21, p. 495-506, 2003.

VIEIRA, R. F.; FONTES, J. R. A. Aplicação da mistura dos herbicidas fomesafen e fluazifop-p-butil por intermédio da água de irrigação de pivô central, na cultura do feijão (Phaseolus vulgaris L.). In: CONGRESSO BRASILEIRO DE INICIAÇÃO CIENTÍFICA EM CIÊNCIAS AGRÁRIAS, 14., 1995, Viçosa, MG. Palestras... Viçosa, MG: Universidade Federal de Viçosa, 1995. p. 176.

WEBER, J. B.; STREK, H. J.; SARTORI, J. L. Mobility of fomesafen and atrazine in soil columns under satured and unsatured flow conditions. Pestic. Sci., v. 39, p. 39-46, 1993. 